\title{
ПОЛИТИЧЕСКАЯ СТАБИЛЬНОСТЬ
}

Семченков А.C.

DOI: 10.7256/2305-560X.2015.2.11570

\section{СИСТЕМНАЯ ДЕСТАБИЛИЗАЦИЯ СОВРЕМЕННЫХ ГОСУДАРСТВ}

\begin{abstract}
Аннотация: Системная дестабилизация государств - феномен современной внутренней и мировой политики, выражающийся в разрушении ранее существовавших социально-политических систем национального уровня социально-культурными, информационными, экономическими, финансовыми, организационно-управленческими, дипломатическими, военными и иными средствами, и в последующей коренной трансрормации этих стран. В статье рассматриваются происхождение и развитие концептов, характеризующих технологии системной дестабилизации современных национальных государств, как федеративных, так и унитарных: управляемый хаос, сетевая война, операции по достижению эффекта, преэмптивная война, геополитическая операция. Принимая во внимание содержание данных концептов, а также особенности мировой политической практики, автор формулирует алгоритм системной дестабилизации, включающий несколько этапов: латентньй, роста напряженности внутри страны и на уровне международных отношений, демонтажа государства-объекта хаотизации. Определяются основные факторы устойчивости государства, подвергающегося системной дестабилизации. На основе учета содержания и особенностей динамики системной дестабилизации сформулирован алгоритм мер и действий по недопущению хаотизации современных государств.
\end{abstract}

Ключевые слова: международные отношения, внешняя политика, государство, дестабилизация, управляемый хаос, сетевая война, преэмптивная война, интересы, безопасность, геополитическая операция.

$\mathrm{C}$ истемная дестабилизация государств - феномен современной внутренней и мировой политики, выражающийся в разрушении ранее существовавших социально-политических систем национального уровня социально-культурными, информационными, экономическими, организационно-управленческими. дипломатическими, военными и иными средствами, а также в последующей коренной трансформации этих стран.

Явление системной дестабилизации отдельных государств давно отмечено исследователями в различных концептах, среди которых можно выделить пять основных: «управляемый хаос», «сетевая война», «операции по достижению эффекта», «преэмптивная война» и «геополитическая операция».

Концепт управляемого хаоса в исследованиях по национальной безопасности был впервые представлен в работе С. Манна «Теория хаоса и стратегическое мышление». В ней данный автор предложил отказаться от тех форм применения военной силы, да и государственной мощи в целом, которые опирались на линейное механистическое видение мира, и обратить внимание на нелинейные хаотические процессы функционирования динамических систем. С точки зрения С. Манна, мировосприятие, опирающееся на выводы из исследований нелиней- ных процессов, целесообразно экстраполировать на политику обеспечения национальной безопасности. Это позволит оптимизировать деятельность государства в сфере национальной стратегии за счет внедрения технологических инноваций и формулирования новых основ стратегического мышления. В качестве нового инструмента ведения войн для США С. Манн рекомендует использование идеологии демократического плюрализма и уважения прав человека как своеобразного вируса, с помощью которого станет возможным получения контроля над общественным сознанием и культурное завоевание других стран. Каналами распространения этой идеологии могут стать американские средства массой коммуникации, охватывающие весь мир, международные образовательные программы различных фондов и т.п. ${ }^{1}$

Содержание концепта управляемого хаоса в дальнейшем обогащалось рядом исследователей, в частности, в России этим плодотворно занима-

\footnotetext{
1 См.: Манн С. Теория хаоса и стратегическое мышление / Пер. Л. Савина // Центр консервативных исследований [Электронный ресурc]. URL: http://konservatizm.org/ konservatizm/theory/080310032055.xhtml. (Дата обращения 02.03.2014).
} 


\section{Международные отношения / International Relations / № 2 / 2015}

ются А.А. Бартош, И.А. Василенко, В.Е. Лепский, А.В. Манойло, И.Ю. Сундиев и др. Данные авторы стали рассматривать управляемый хаос (контролируемую нестабильность) как более сложный процесс, который помимо идейного и культурного измерений стал включать в себя информационно-психологическую, экономическую, финансовую, дипломатическую и вооруженную борьбу. Очевидно, импульсом к анализу управляемого хаоса именно как многомерного процесса послужили такие события, как распад Югославии и война международной коалиции во главе с США с этой страной в 1999 г., вторжение многонациональных сил в Ирак в 2003 г., «цветные революции», «арабская весна».

В этой связи А.А. Бартош полагает, что управляемый хаос представляет собой инструмент глобального доминирования, программу действий по целенаправленной организации и координации развития процессов в стране-объекте управления по конфронтационной спирали для перевода этого государства на заданные социально-политические, военные, экономические, пространственно-географические параметры функционирования. В конечном счете, субъект управления преследует цель по созданию предпосылок к самодезориентации и самодезорганизации ввергаемой в контролируемую нестабильность страны. Механизмами достижения этой цели, по мнению А. Бартоша, служат установление либеральной демократии и проведение рыночных реформ, внедрение стандартов общества потребления среди элит и масс, вытеснение из общественного сознания традиционных ценностей и идей, культурное переформатирование общества, деиндустриализация, разрушение системы профессионального образования, поощрение коррупции, создание благоприятных условий для существования несистемной оппозиции и экстремистских организаций. Последние организуются в локальные и региональные сети, и в дальнейшем, по мере усиления нестабильности, используются для смены власти в стране-объекте управления. Многие механизмы запуска управляемого хаоса создаются заблаговременно.

Исследователь полагает, что объектами воздействия в модели управляемого хаоса являются структуры государства, определяющие его роль и место в современном мире: органы военно-политического управления, социально-экономический и военный потенциал, инфраструктура, территория и население. Главный объект хаотизации - политические и бизнес-элиты страны, органы государственного управления, которые под влиянием технологий информационно-психологического воздействия должны переориентировать развитие государства и общества на стратегически бесперспективные и экономически неэффективные направления. Важной составляющей управляемого хаоса также выступает работа с молодежью, чьи ценностные установки и идейные ориентации постепенно подвергаются вестернизации ${ }^{2}$.

Несколько иначе управляемый хаос рассматривается В.Е. Лепским. Он считает данного рода процесс мировой информационно-психологической войной, направленной на сокращение численности населения в странах, не входящих в «золотой миллиард», а также ослабление и разрушение национальных государств как «мягкими» технологиями, так и путем военной агрессии. В основу управляемого хаоса положено переформатирование массового сознания и мировоззрения за счет использования манипулятивных информационных и социально-культурных технологий. В обществе разрушаются связи солидарности, происходит его атомизация. Разрушается и субъектность развития демонтируемых посредством управляемого хаоса государств, которые перестают быть конкурентами развитых стран мира 3 .

Происхождение концепта «сетевая война» также связано с разработкой в США «сетецентрических» форм ведения боевых действий (Дж. Гарстка и А. Себровски) и переносом методологии новых способов ведения вооруженной борьбы на сферу межгосударственных отношений и геополитического противоборства в целом. Данная задача по экстраполяции принципов «сетецентрических» боевых действий в область национальной стратегии была решена Э. Смитом.

Им был предложен концепт «операции по достижению эффекта» (иной перевод - «операции по достижению эффективности», «операции базовых

\footnotetext{
2 Подробнее об этом см.: Бартош А. Модель «управляемого хаоса» - угроза национальной безопасности России // Независимое военное обозрение. 12 июля 2013 г. [Электронный pecypc]. URL: http://nvo.ng.ru/concepts/2013-07-12/4_chaos. html. (Дата обращения 02.03.2014); Он же. Цель и механизмы модели "управляемого хаоса» // Независимое военное обозрение. 27 сентября 2013 г. [Электронный ресурc]. URL: http://nvo.ng.ru/concepts/2013-09-27/6_chaos.html. (Дата обращения 02.03.2014).

3 См.: Лепский В.Е. Технологии управляемого хаоса - оружие разрушения субъектности развития // Сайт С.П. Курдюмова [Электронный ресурс]. URL: http://spkurdyumov. $\mathrm{ru} /$ what/texnologii-upravlyaemogo-haosa/. (Дата обращения 02.03.2014).
} 
эффектов»; Effect Based Operations), который зачастую и отождествляется с концептом сетевых войн. Э. Смит подчеркивает, что это «скоординированная цепь действий, направленных на формирование поведения своей стороны, противника и нейтральных сторон в условиях мира, кризиса и войны». «Операции по достижению эффекта» разновидность военных и невоенных действий правительственных структур и негосударственных организаций, предполагающих использование всех компонентов национальной мощи, но с ускоренным темпом и значительным масштабом для «истощения» и «предрешения» (предотвращения и недопущения) активных ответных действий оппонента. Фактически «операции по достижению эффекта» направлены на подрыв воли противника продолжать борьбу, его дезориентацию и утрату им способности реагировать адекватно. Акцент при этом делается не на физическом уничтожении, а на психологических (когнитивных) последствиях-эффектах для сознания руководства противостоящего государства. Учет когнитивных эффектов позволяет управлять поведением как противника, удерживаемого от определенных действий, так и дружественных и нейтральных стран, от которых добиваются поддержки ${ }^{4}$.

Среди различных видов операций, основанных на эффекте, задачи по системной дестабилизации государств позволяют решить операции стратегического уровня. Они ведут к уничтожению, физическому истощению (постепенному лишению противника возможностей продолжать военные действия), хаосу (одновременно физическому и психологическому последствию-эффекту, заключающемуся в дезориентации, панике, дезорганизации сил противника, утрате его руководством способности адекватно реагировать и контролировать свои силы), шоку (деморализации солдат и панике, параличу руководства противника, его отказу от активных действий), активному и пассивному предрешению (психологическому последствиюэффекту в форме предотвращения или недопущения каких-либо действий со стороны противника в результате использования вооруженных сил или угрозы применения силы для блокирования намеченного реальным или потенциальным противником курса действий, поддержания такого баланса сил, который обеспечивает стабильность в данном

4 Попов И.М. Война будущего: взгляд из-за океана: Военные теории и концепции современных США. М.: АСТ: Астрель: Транзиткнига, 2004. С. 261. регионе мира) противника. Цель операций стратегического уровня заключается в бескровном влиянии на оппонента. Пассивное предрешение может быть реализовано в форме невыгодного для государства-оппонента соотношения (баланса) сил на региональном уровне или внутри страны. Активное предрешение имеет непосредственный характер и воплощается в проведении молниеносных военных действий по разгрому противника, терроризме, «ненасильственных» переворотах, разжигании внутригосударственных конфликтов ${ }^{5}$.

В России концепт сетевой войны разрабатывается рядом исследователей, среди которых можно выделить А.Г. Дугина, В.М. Коровина и А.Л. Бовдунова.

Данные авторы рассматривают сетевую войну как противоборство между, прежде всего, институализированными и неформальными глобальными структурами, а затем уже государствами и их блоками. Сеть из технического средства обмена разнообразной информацией превратилась в основу современного социума, а также пространство идеологического и информационно-психологического противоборства, в котором принимают участие масс-медиа, неправительственные общественные и религиозные организации, транснациональные корпорации, спецслужбы различных государств. Сетевая война предстает как форма организации и контроля над глобальными процессами в выгодном для США русле. Сетевая война ведется как против оппонентов Соединенных Штатов, так и против нейтральных и союзных для них государств. Цель сетевой войны состоит в установлении, прежде всего, информационного и когнитивного контроля над этими категориями стран. Примерами ведения сетевых войн, в которых собственно и проявилась системная дестабилизация государств, авторы считают «цветные революции» в Сербии, Грузии, Украине, Киргизии и вооруженные конфликты в Ираке и Афганистане, завершившиеся сменой неугодных США политических режимов и элит ${ }^{6}$.

\footnotetext{
Подробнее об этом см.: Smith E.A. Effects Based Operations: Applying Network Centric Warfare in Peace, Crisis, and War. Center for Advanced Concepts and Technology. Washington, D.C.: DOD-CCRP, 2002. November; Попов И.М. Война будущего: взгляд из-за океана: Военные теории и концепции современных США. М.: АСТ: Астрель: Транзиткнига, 2004. C. 260.

6 Подробнее об этом см.: Дугин А., Коровин В., Бовдунов А. Сетевые войны // Сайт С.П. Курдюмова [Электронный ресурс]. URL: http://spkurdyumov.ru/networks/setevye-vojny/4/. (Дата обращения 02.03.2014).
} 


\section{Международные отношения / International Relations / № 2 / 2015}

Концепт «преэмптивная война» берет свое начало в Стратегии национальной безопасности США, принятой в 2002 г. президентом Дж. Бушеммладшим. Согласно Стратегии, преэмптивная война предполагала упреждающую нейтрализацию не просто угроз национальной безопасности Соединенных Штатов до их возникновения в будущем, а самих их субъектов - «государств-изгоев», которые надлежало трансформировать из диктатур в демократии. В России анализ этого концепта, в частности, провели Ю.В. Крупнов и Н.А. Комлева.

Ю.В. Крупнов отмечает, что преэмпция означает опережающий захват или силовое действие на опережение, т.е. опережающую нейтрализацию не только самой угрозы, но и ее факторов, источников, вплоть до самого ее субъекта - государства или террористической организации. Преэмптивная война, таким образом, предполагает, во-первых, смену политического режима в странесубъекте угроз (regime change), во-вторых, строительство на месте бывшей диктатуры новой нации (nation-building) и, в-третьих, восстановление страны (nation-remaking). Системная дестабилизация в рамках преэмптивной войны приходится на фазу смены политического режима. Вместе с тем, как показывает опыт ведения преэмптивных войн, например, в Афганистане и Ираке, политическая и экономическая неустойчивость характерна и для стран, находящихся в фазах строительства новых наций и восстановления.

По мнению Н.А. Комлевой, преэмптивная война является геополитической технологией контроля пространств и ресурсов, передела мира в интересах глобальных корпораций и государств их базирования. Объектами преэмптивной войны выступают страны, богатые ценными природными ресурсами (в первую очередь, энергетическим сырьем), распоряжение которыми навечно закрепляется за победителями ${ }^{7}$.

Наглядным примером проведения преэмптивной войны выступает вторжение США и их союзников в Афганистан в 2001 г., Ирак в 2003 г., Ливию в 2011 г. и дальнейшие социально-политические и экономические преобразования в этих странах, проведенные государствами-победителями. Однако Ю.В. Крупнов полагает, что начало преэмптив-

\footnotetext{
Подробнее об этом см.: Комлева Н.А. Преэмптивная война как технология ресурсного передела мира // [Электронный ресурc]. URL: http://akademiagp.ru/preemptivnaya-vojnakak-texnologiya-resursnogo-peredela-mira/. (Дата обращения 02.03.2014).
}

ной войны как стратегии трансформации всего мира просматривается уже с 1992 г. в связи с распадом СССР и курсом США на создание глобальной империи ${ }^{8}$.

Концепт «геополитическая операция» изначально предложен и разрабатывается российскими исследователями Л.Г. Ивашовым и К.В. Сивковым. По целому ряду признаков он близок концептам управляемого хаоса, сетевой и преэмптивной войны. Геополитическая операция рассматривается как новая высшая форма межгосударственного противоборства на глобальном и региональном уровне со своими этапами подготовки и проведения, которая превосходит военные действия по охватываемому пространству, количеству и разнообразию привлекаемых сил и средств. Цели геополитической операции - ликвидация геополитического противника или смена власти в той или иной стране. Содержание геополитической операции составляют операции и боевые действия группировок вооруженных сил и иррегулярных формирований, тайные операции спецслужб, мероприятия экономической войны, дипломатической и информационной борьбы, иных структур. Примерами этих форм действий в межгосударственном противоборстве служат осуществленные Западом восточноевропейские (завершились распадом блока социалистических стран и расширением НАТО на восток), Евроазиатская (закончилась дезинтеграцией СССР), Восточно-Азиатская (попытка установления контроля над Ираком и Афганистаном) и Североафриканская - «арабская весна» (смена режимов в странах Магриба) операции ${ }^{9}$. Данные примеры показывают, что системная дестабилизация государств осуществляется в течение всего времени проведения геополитической операции.

Обобщая содержание рассмотренных выше концептов, можно дать следующее определение понятия системной дестабилизации государства: это нарушение устойчивости существования и развития, демонтаж государственности той или иной страны как территориальной социально-политической системы социокультурными, информационно-психологическими, экономическими, финансовыми, организационно-управленческими, дипломатическими, силовыми и иными средствами, осуществляемые с

\footnotetext{
8 Подробнее об этом см.: Крупнов Ю. Преэмптивная война // Сайт Ю. Крупнова [Электронный ресурс]. URL: http:// www.kroupnov.ru/5/30_1.shtml. (Дата обращения 02.03.2014).

9 Подробнее об этом см.: Сивков К. По новым правилам // Военно-промышленный курьер. 2013. № 4 (472).
} 
учетом ее внутренних дисфункций в рамках межгосударственного противоборства. В настоящее время основной акцент в системной дестабилизации делается на проведении информационно-психологических операций в рамках сетевых коммуникаций. В то же время при решении задач хаотизации сохраняют свое значение тайные операции спецслужб и военные действия армий державы-субъекта дестабилизации и ее союзников.

В целом, анализ содержания концептов управляемого хаоса, сетевой и преэмптивной войн, операций по достижению эффекта, геополитической операции, а также мировая политическая практика показывают, что системная дестабилизация государств осуществляется в рамках межгосударственных и внутригосударственных конфликтов, одновременно проходящих и тесно взаимосвязанных по участвующим сторонам, целям и средствам. Обобщенно в динамике системной дестабилизации государств можно выделить следующие этапы.

Латентный этап характеризуется всесторонней подготовкой условий для системной дестабилизации, инициирования внутренних столкновений и межгосударственного конфликта, планированием их развития, подготовкой основных инструментов их реализации и противоборства в различных сферах. В частности, в самой стране-объекте предполагаемой системной дестабилизации формируются и начинают вести широкую пропаганду для привлечения новых сторонников экстремистские организации и движения, налаживается сотрудничество между структурами несистемной оппозиции. Постепенно формируются предпосылки к социально-экономическому кризису и вызревают условия роста напряженности в межэтнических и межконфессиональных отношениях. Также держава-субъект дестабилизации ведет всестороннюю разведку возможностей государства-объекта на фоне официальных относительно мирных, стабильных отношений между ними.

На этапе роста напряженности внутри страны-объекта хаотизации осуществляются акции по дестабилизации социально-политической обстановки, интенсифицируется протестная активность отдельных групп населения. Начинают открыто действовать экстремистские организации и несистемная оппозиция, ведущие антиправительственную пропаганду. Одновременно субъектом дестабилизации организуются военные коалиции, осуществляется информационно-психологическое, дипломатическое, экономическое, военно-политическое давление на обороняющееся государство, его союзников, партнеров, все международное сообщество с целью апологии необходимости вторжения на его территорию, снижение его международного престижа, создание негативного образа страны-объекта агрессии. В ее отношении вводятся экономические санкции, возможны блокада и международная изоляция, проводится подготовка вооруженных сил агрессивной стороны к нападению. На этом же этапе агрессивной стороной развязываются и провоцируются локальные военные конфликты на границах и территории самой обороняющейся стороны или ее союзников. Особенностью данного этапа является возможность его весьма большой длительности, высокой амплитуды, смены периодов относительно мирной обстановки ее обострением, что позволяет субъекту дестабилизации постепенно добиваться своих военно-политических, экономических и иных целей без масштабного применения военной силы.

Этап демонтажа государства начинается с перехода к насильственным действиям экстремистских и террористических сетей против органов власти и граждан, официально объединяются различные с идейно-политической точки зрения структуры несистемной оппозиции. Последней начинает явно оказываться всесторонняя поддержка державой-субъектом дестабилизации. Успешное сопротивление государства-объекта дестабилизации силам деструктивного толка предопределяет переход субъекта хаотизации к военной агрессии. Предваряя ее, субъект дестабилизации может инициировать информационнотехническое противоборство и ведение непрямых действий силами вторжения (либо экстремистскими и террористическими формированиями) по выводу из строя критической инфраструктуры страны (систем экономики, банковского сектора, продовольственного обеспечения, энергетики, транспорта, связи) с тем, чтобы оказать давление на население и подтолкнуть его к массовым протестным акциям. Осуществляется и вывод из строя систем государственного и военного управления. Руководство страны, политическая и экономическая элита общества также подвергаются внешнему дипломатическому, экономическому и информационно-психологическому давлению, среди их представителей ведется поиск союзников в деле подрыва конституционного строя. Этап завершается собственно вооруженным вторжением в страну-объект хаотизации, успех которого определяется решением задач по системной дестабилизации на предыдущих этапах. 
Анализ динамики системной дестабилизации показывает, что основными факторами устойчивости государства, подвергающегося деструктивному воздействию, являются: идейно-ценностная сфера общества, состояние социально-экономической, межэтнической и межконфессиональной стабильности, уровень поддержки обществом политического режима; система государственного управления, инфраструктура жизнеобеспечения, военная организация; система международных связей и отношений государства с другими державами - союзниками, партнерами, соседями и оппонентами в конфликте.

Данные факторы одновременно выступают и объектами защиты государства-объекта дестабилизации, которое вынуждено реагировать на действия агрессора. Условием срыва мероприятий системной дестабилизации является удержание контроля государства-объекта над данными факторами на латентном этапе и этапе роста напряженности.

Учитывая содержание и особенности динамики системной дестабилизации, можно сформулировать следующий алгоритм мер и действий по недопущению хаотизации государства-объекта.

Латентный этап системной дестабилизации характеризуется реализацией большинства мер и действий стратегии по обеспечению национальной безопасности страны-объекта. Главные мероприятия по недопущению контролируемой нестабильности - меры и действия государства и общества по защите ценностных и идейных основ, «культурного ядра» страны - целесообразно проводить именно на этом этапе. Защита «культурного ядра» страны включает в себя сохранение системы духовных ценностей и исторической памяти, идентичности гражданской нации, а также проведение информационных кампаний по формированию позитивного образа страны и мероприятий ограничительного и запретительного характера по отношению к деструктивному духовному и информационному воздействию на общество. Заблаговременность реализации подобных защитных мер позволяет нейтрализовать тот комплекс идей, который в последующем составит базис направленной против конституционного строя государства-объекта дестабилизации информационной кампании экстремистских организаций и несистемной оппозиции.

В области обеспечения внутриполитической стабильности представляется продуктивной реализация тех форм деполитизации и снижения проти- воречий между социальными слоями, этническими группами, религиозными общинами, общегосударственной и региональными элитами, которые обеспечили бы гражданский мир и территориальную целостность страны в долгосрочной перспективе. Наряду с этим целесообразно не допустить формирования экстремистских и террористических сетей на территории государства, не позволить начать им вести агитацию и пропаганду для привлечения все большего числа сторонников в свои ряды.

В латентный период вооруженные силы обеспечивают стратегическое сдерживание агрессии против государства-объекта системной дестабилизации боевым составом мирного времени. Государство-объект дестабилизации снижает уровень внешних военных опасностей и угроз посредством создания системы межгосударственных союзнических связей в области международной безопасности. Превентивными действиями являются участие государства в военно-политических союзах с другими заинтересованными в совместном отражении возможной агрессии державами, в системах коллективной безопасности. Снижению военной опасности отвечает реализация государством мер доверия и условий международных договоров в сфере безопасности (о стратегических наступательных вооружениях, ограничении обычных вооруженных сил и т.п.) с потенциальными противниками и оппонентами.

На предупреждение межгосударственных конфликтов, формирование пояса дружественных или нейтральных стран вокруг границ государствомобъектом дестабилизации может быть направлено и его участие в международных экономических объединениях, поддержание стратегических партнерских отношений в сфере энергетического сотрудничества со странами-оппонентами.

Для ослабления силового давления и военнополитических возможностей своих визави государство-объект дестабилизации может развивать военно-техническое или полномасштабное военное сотрудничество с государствами, находящимися с ними в напряженных отношениях и способными отвлечь на себя их значительные силы.

На латентном этапе наиболее эффективными являются и действия по дезорганизации постоянно существующих военно-политических блоков и коалиций противостоящих держав, проведение в отношении них стратегии непрямых действий экономического и политического характера.

Следуя этим шагам, государство-объект дестабилизации может выстраивать необходимую для 
обеспечения своей безопасности систему равновесия сил в мире.

На этапе роста напряженности продуктивны информационно-психологические операции по консолидирующей пропаганде среди населения государства-объекта системной дестабилизации. В информационном пространстве стран-союзников и партнеров, других членов международного сообщества могут быть проведены имиджевые операции в поддержку действий руководства страны-объекта хаотизации по предотвращению войн и других международных конфликтов. Целесообразны и мероприятия контрпропаганды в информационной среде агрессора, его союзников и партнеров по коалиции. Также важными мероприятиями на этапе роста напряженности являются действия по срыву конфликтной политической, этнической или религиозной мобилизации различных групп населения страны или отдельных местностей, служащей предварительным условием для подъема массового протестного движения, беспорядков и проведения неконституционной смены власти в стране.

Реализация государством-объектом системной дестабилизации мер антикризисного реагирования в сфере обеспечения внутриполитической стабильности посредством оперативной нейтрализации акций сохранившихся террористических, сепаратистских и экстремистских организаций позволяет предотвратить внутренние столкновения, дестабилизирующие межэтнические, межконфессиональные и иные общественные отношения. Операции по защите конституционного строя в случае необходимости могут проводиться и на территории союзников и партнеров государства-объекта дестабилизации.

Для отражения вооруженной агрессии и организованного вступления в войну вооруженные силы государства-объекта дестабилизации и его союзников могут быть переведены в более высокие степени боевой готовности и приступить к осуществлению более масштабных и продолжительных мероприятий боевой и оперативной подготовки.

Большое значение на данном этапе приобретают дипломатические меры, обеспечивающие распад коалиций потенциального агрессора, его изоляции в международном сообществе. Государством-объектом хаотизации также могут осуществляться дипломатические, экономические и военные действия по недопущению своей изоляции и блокады с воздушных, наземных и морских направлений, диверсификации собственных международных экономических и иных связей. Государство-объект может также принять участие в локальных военных конфликтах далеко за пределами своей территории, продемонстрировав там высокий уровень боеспособности своих войск как меру силового сдерживания агрессии. Стратегическое сдерживание агрессии против государстваобъекта дестабилизации проводится силами боевого состава мирного времени, а основную роль в срыве агрессии начинают играть неядерные высокоточные системы, боеготовность которых может быть повышена.

На этапе демонтажа государства поддержание внутриполитической стабильности и территориальной целостности страны может быть обеспечено за счет систематической ликвидации сохранившихся ячеек и подразделений экстремистских и террористических сетей, их изоляции от подполья как на территории охваченных внутригосударственными конфликтами регионов, так и за их пределами. Кроме того для обеспечения политической стабильности по-прежнему целесообразно проведение мероприятий по консолидации общества на базе принципов гражданского мира, межнационального и межконфессионального согласия.

Этап демонтажа государства в сфере межгосударственного противоборства, характеризующийся переходом от локальных приграничных конфликтов к региональной или крупномасштабной войне, предполагает защиту систем государственного и военного управления, критической инфраструктуры страны и реализацию мер по срыву и деэскалации вооруженной агрессии.

На этапе демонтажа государства задача дезорганизации противостоящей коалиции может быть решена либо путем создания угрозы ее разгрома, либо путем нанесения поражения ее ведущей державе, большинству его союзников. В свою очередь, государство-объект дестабилизации и его союзники совместно отражают вооруженную агрессию.

Вслед за началом вооруженной агрессии для государства-объекта дестабилизации вполне оправданной является блокада транспортных, энергетических коммуникаций противника, либо, если потенциал этой меры исчерпан, воспрещение внешней торговли страны-визави путем проведения морских, воздушных и наземных операций.

На данном этапе по мере дальнейшей эскалации вооруженной борьбы целесообразно последовательное использование всех известных форм стратегического силового сдерживания. В начале оптимальна демонстрация развертывания груп- 


\section{Международные отношения / International Relations / № 2 / 2015}

пировок войск на ожидаемых направлениях вторжения. Если эти действия не обеспечили деэскалацию вооруженного конфликта, возможен переход к нанесению ответных неядерных противосиловых и обезглавливающих ударов по войскам, инфраструктуре и системам управления ${ }^{10}$, а также противоценностных ударов по второстепенным целям на территории противника. Последней мерой в этом ряду, если государство-объект дестабилизации располагает ядерным оружием, остается стратегическое ядерное сдерживание на региональном и глобальном уровне в форме неконвенциональных ограниченных ударов по объектам и районам, не относящимся к территории и населению страны-противника. Нанесение непрямого заданного ущерба в результате нанесения этих ударов заставит противника осознать бесперспективность его вооруженного вторжения.

Думается, что реализация государством данного комплекса мер и действий позволит не только не допустить перехода системной дестабилизации из латентной фазы в фазу роста напряженности, но и выйти из политического кризиса мирным путем. По крайней мере, следование данной системе мер не приведет, как нам представляется, к инициированию внутренних конфликтов и вооруженному столкновению вследствие понимания государством-субъектом системной дестабилизации невозможности решения в его итоге намеченных политических, экономических и иных задач.

\section{Библиография:}

1. Манн С. Теория хаоса и стратегическое мышление / Пер. Л. Савина // Центр консервативных исследований [Электронный ресурс]. URL: http://konservatizm.org/konservatizm/theory/080310032055.xhtml. (Дата обращения 02.03.2014).

2. Бартош А. Модель «управляемого хаоса»-угроза национальной безопасности России // Независимое военное обозрение. 12 июля 2013 г. [Электронный ресурc]. URL: http://nvo.ng.ru/concepts/2013-07-12/4_chaos.html. (Дата обращения 02.03.2014);

3. Бартош А. Цель и механизмы модели «управляемого хаоса» // Независимое военное обозрение. 27 сентября 2013 г. [Электронный ресурс]. URL: http://nvo.ng.ru/concepts/2013-09-27/6_chaos.html. (Дата обращения 02.03.2014).

4. Лепский В.Е. Технологии управляемого хаоса - оружие разрушения субъектности развития // Сайт С.П. Курдюмова [Электронный ресурс]. URL: http://spkurdyumov.ru/what/texnologii-upravlyaemogo-haosa/. (Дата обращения 02.03.2014).

5. Попов И.М. Война будущего: взгляд из-за океана: Военные теории и концепции современных США. М.: АСТ: Астрель: Транзиткнига, 2004. С. 261.

6. Подробнее об этом см.: Smith E.A. Effects Based Operations: Applying Network Centric Warfare in Peace, Crisis, and War. Center for Advanced Concepts and Technology. Washington, D.C.: DOD-CCRP, 2002. November;

7. Дугин А., Коровин В., Бовдунов А. Сетевые войны // Сайт С.П. Курдюмова [Электронный pecypc]. URL: http:// spkurdyumov.ru/networks/setevye-vojny/4/. (Дата обращения 02.03.2014).

8. Комлева H.A. Преэмптивная война как технология ресурсного передела мира // [Электронный pecypc]. URL: http:// akademiagp.ru/preemptivnaya-vojna-kak-texnologiya-resursnogo-peredela-mira/. (Дата обращения 02.03.2014).

9. Крупнов Ю. Преэмптивная война // Сайт Ю. Крупнова [Электронный ресурc]. URL: http://www.kroupnov. ru/5/30_1.shtml. (Дата обращения 02.03.2014).

10. Сивков К. По новым правилам // Военно-промышленный курьер. 2013. № 4 (472).

11. Богданов С.А. Вероятный облик вооруженной борьбы будущего // Военная мысль. 2003. №

12. С. 2-7. 12.Марценюк Ю.А. Основные тенденции изменения характера войн и вооруженных конфликтов (По опыту военных конфликтов второй половины XX и начала XXI века) // Вестник Академии военных наук. 2005. № 2. C. 134-139.

13. Бородинов Е.Н. Причины и следствия государственного переворота на Украине // NB: Международные отношения.-2014.-3.-C. 36-59. DOI: 10.7256/2306-4226.2014.3.11501. URL: http://www.e-notabene.ru/wi/ article_11501.html

14. Манойло А.В. Стратегии «управляемого хаоса» в условиях хаотизации международных отношений: миф или реальность? // NB: Международные отношения.-2014.-1.-C. 1-3. DOI: 10.7256/2306-4226.2014.1.10750. URL: http:// www.e-notabene.ru/wi/article_10750.html

15. Филиппов B.P. Буркина Фасо: политический кризис 2011 года // Международные отношения.-2013.-4.-С. 424438. DOI: 10.7256/2305-560X.2013.4.9721.

10 Подробнее см.: Богданов С.А. Вероятный облик вооруженной борьбы будущего // Военная мысль. 2003. № 12. С. 2-7; Марценюк Ю.А. Основные тенденции изменения характера войн и вооруженных конфликтов (По опыту военных конфликтов второй половины XX и начала XXI века) // Вестник Академии военных наук. 2005. № 2. С. 134-139. 


\section{Политическая стабильность / Political Stability}

16. Семченков А.С.. Современные сценарии политической дестабилизации России. // Международные отношения.-2013.-№ 3.-С. 345-352. DOI: .10.7256/2305-560Х.2013.3.8816

17. Е. Е. Прокопенко. Роль конфликтогенного компонента в полиэтничном Северо-Кавказском федеральном округе. // Политика и Общество.-2012.-№ 1.-С. 58-64.

18. П.С. Гуревич. Социальный хаос в толковании Ж. Бодрийяра. // Философия и культура.-2013.-№ 8.-С. $1043-1046$. DOI: .10.7256/1999-2793.2013.8.9412

19. Э. А. Орлова. Синергетические идеи в изучении социокультурной микродинамики. // Культура и искусство.-2012.-№ 4.-С. 18-31.

\section{References (transliterated):}

1. Mann S. Teoriya khaosa i strategicheskoe myshlenie / Per. L. Savina // Tsentr konservativnykh issledovanii [Elektronnyi resurs]. URL: http://konservatizm.org/konservatizm/theory/080310032055.xhtml. (Data obrashcheniya 02.03.2014).

2. Bartosh A. Model' «upravlyaemogo khaosa»-ugroza natsional'noi bezopasnosti Rossii // Nezavisimoe voennoe obozrenie. 12 iyulya 2013 g. [Elektronnyi resurs]. URL: http://nvo.ng.ru/concepts/2013-07-12/4_chaos.html. (Data obrashcheniya 02.03.2014);

3. Bartosh A. Tsel' i mekhanizmy modeli «upravlyaemogo khaosa» // Nezavisimoe voennoe obozrenie. 27 sentyabrya 2013 g. [Elektronnyi resurs]. URL: http://nvo.ng.ru/concepts/2013-09-27/6_chaos.html. (Data obrashcheniya 02.03.2014).

4. Lepskii V.E. Tekhnologii upravlyaemogo khaosa - oruzhie razrusheniya sub"ektnosti razvitiya // Sait S.P. Kurdyumova [Elektronnyi resurs]. URL: http://spkurdyumov.ru/what/texnologii-upravlyaemogo-haosa/. (Data obrashcheniya 02.03.2014).

5. Popov I.M. Voina budushchego: vzglyad iz-za okeana: Voennye teorii i kontseptsii sovremennykh SShA. M.: AST: Astrel': Tranzitkniga, 2004. S. 261.

6. Podrobnee ob etom sm.: Smith E.A. Effects Based Operations: Applying Network Centric Warfare in Peace, Crisis, and War. Center for Advanced Concepts and Technology. Washington, D.C.: DOD-CCRP, 2002. November;

7. Dugin A., Korovin V., Bovdunov A. Setevye voiny // Sait S.P. Kurdyumova [Elektronnyi resurs]. URL: http://spkurdyumov. $\mathrm{ru} /$ networks/setevye-vojny/4/. (Data obrashcheniya 02.03.2014).

8. Komleva N.A. Preemptivnaya voina kak tekhnologiya resursnogo peredela mira // [Elektronnyi resurs]. URL: http:// akademiagp.ru/preemptivnaya-vojna-kak-texnologiya-resursnogo-peredela-mira/. (Data obrashcheniya 02.03.2014).

9. Krupnov Yu. Preemptivnaya voina // Sait Yu. Krupnova [Elektronnyi resurs]. URL: http://www.kroupnov.ru/5/30_1. shtml. (Data obrashcheniya 02.03.2014).

10. Sivkov K. Po novym pravilam // Voenno-promyshlennyi kur'er. 2013. № 4 (472).

11. Bogdanov S.A. Veroyatnyi oblik vooruzhennoi bor'by budushchego // Voennaya mysl'. 2003. №

12. S. 2-7. 12.Martsenyuk Yu.A. Osnovnye tendentsii izmeneniya kharaktera voin i vooruzhennykh konfliktov (Po opytu voennykh konfliktov vtoroi poloviny XX i nachala XXI veka) // Vestnik Akademii voennykh nauk. 2005. № 2. S. 134-139.

13. Borodinov E.N. Prichiny i sledstviya gosudarstvennogo perevorota na Ukraine // NB: Mezhdunarodnye otnosheniya.2014.-3.-C. 36-59. DOI: 10.7256/2306-4226.2014.3.11501. URL: http://www.e-notabene.ru/wi/article_11501.html

14. Manoilo A.V. Strategii «upravlyaemogo khaosa» v usloviyakh khaotizatsii mezhdunarodnykh otnoshenii: mif ili real'nost'? // NB: Mezhdunarodnye otnosheniya.-2014.-1.-C. 1-3. DOI: 10.7256/2306-4226.2014.1.10750. URL: http://www.enotabene.ru/wi/article_10750.html

15. Filippov V.R. Burkina Faso: politicheskii krizis 2011 goda // Mezhdunarodnye otnosheniya.-2013.-4.-C. 424-438. DOI: $10.7256 / 2305-560 X .2013 .4 .9721$.

16. Semchenkov A.S.. Sovremennye stsenarii politicheskoi destabilizatsii Rossii. // Mezhdunarodnye otnosheniya.-2013.№ 3.-C. 345-352. DOI: .10.7256/2305-560X.2013.3.8816

17. E. E. Prokopenko. Rol' konfliktogennogo komponenta v polietnichnom Severo-Kavkazskom federal'nom okruge. // Politika i Obshchestvo.-2012.-№ 1.-C. 58-64.

18. P.S. Gurevich. Sotsial'nyi khaos v tolkovanii Zh. Bodriiyara. // Filosofiya i kul'tura.-2013.-№ 8.-C. 1043-1046. DOI: .10.7256/1999-2793.2013.8.9412

19. E. A. Orlova. Sinergeticheskie idei v izuchenii sotsiokul'turnoi mikrodinamiki. // Kul'tura i iskusstvo.-2012.-№ 4.-C. 18-31. 